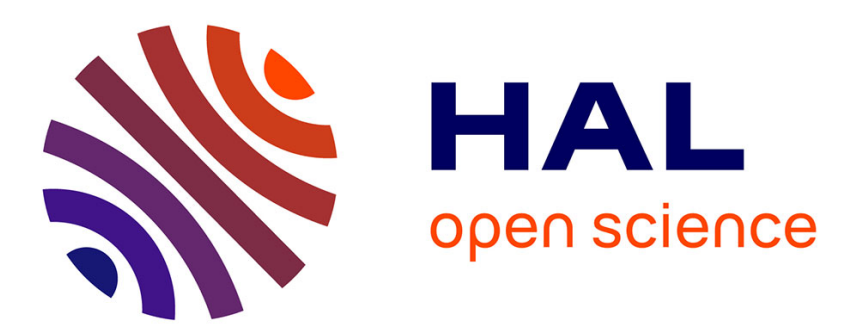

\title{
Toward relaxed eddy accumulation measurements of sediment-water exchange in aquatic ecosystems
}

\author{
Bruno J. Lemaire, Christian Noss, Andreas Lorke
}

\section{To cite this version:}

Bruno J. Lemaire, Christian Noss, Andreas Lorke. Toward relaxed eddy accumulation measurements of sediment-water exchange in aquatic ecosystems. Geophysical Research Letters, 2017, 44 (17), pp.8901-8909. 10.1002/2017GL074625 . hal-01592668

\section{HAL Id: hal-01592668 \\ https://hal-enpc.archives-ouvertes.fr/hal-01592668}

Submitted on 16 Nov 2017

HAL is a multi-disciplinary open access archive for the deposit and dissemination of scientific research documents, whether they are published or not. The documents may come from teaching and research institutions in France or abroad, or from public or private research centers.
L'archive ouverte pluridisciplinaire HAL, est destinée au dépôt et à la diffusion de documents scientifiques de niveau recherche, publiés ou non, émanant des établissements d'enseignement et de recherche français ou étrangers, des laboratoires publics ou privés. 


\section{Geophysical Research Letters}

\section{RESEARCH LETTER}

10.1002/2017GL074625

Key Points:

- Applicability of relaxed eddy accumulation (REA) to measure solute fluxes across the sediment-water interface was assessed

- The empirical coefficient in flux calculations is similar for heat, oxygen, and particles and does not change with flow

- REA has the potential to provide flux estimates for a broad range of substances in aquatic ecosystems but may be limited by analytical precision

Supporting Information:

- Supporting Information S1

Correspondence to:

B. J. Lemaire,

bruno.lemaire@leesu.enpc.fr

\section{Citation:}

Lemaire, B. J., C. Noss, and A. Lorke (2017), Toward relaxed eddy accumulation measurements of sediment-water exchange in aquatic ecosystems, Geophys. Res. Lett., 44, doi:10.1002/ 2017 GL074625.

Received 18 JUN 2017 Accepted 9 AUG 2017 Accepted article online 11 AUG 2017

(C2017. American Geophysical Union. All Rights Reserved.

\section{Toward relaxed eddy accumulation measurements of sediment-water exchange in aquatic ecosystems}

\author{
Bruno J. Lemaire ${ }^{1}$ (D) Christian Noss ${ }^{2}$ (D) and Andreas Lorke ${ }^{2}$ (D) \\ ${ }^{1}$ LEESU, AgroParisTech, Ecole des Ponts, UPEC, UPE, Marne-la-Vallée, France, ${ }^{2}$ Institute for Environmental Sciences, \\ University of Koblenz-Landau, Landau, Germany
}

Abstract Solute transport across the sediment-water interface has major implications for water quality and biogeochemical cycling in aquatic ecosystems. Existing measurement techniques, however, are not capable of resolving sediment-water fluxes of most constituents under in situ flow conditions. We investigated whether relaxed eddy accumulation (REA), a micrometeorological technique with conditional sampling of turbulent updrafts and downdrafts, can be adapted to the aquatic environment. We simulated REA fluxes by reanalyzing eddy covariance measurements from a riverine lake. We found that the empirical coefficient that relates mass fluxes to the concentration difference between both REA samples is invariant with scalar and flow and responds as predicted by a joint Gaussian distribution of linearly correlated variables. Simulated REA fluxes differed on average by around 30\% from eddy covariance fluxes (mean absolute error). Assessment of the lower quantification limit suggests that REA can potentially be applied for measuring benthic fluxes of a new range of constituents that cannot be assessed by standard eddy covariance methods.

\section{Introduction}

The exchange of dissolved and particle-bound organic matter, mineralization products, and pollutants across the sediment-water interface is of paramount importance for the ecology, biogeochemistry, and water quality in aquatic ecosystems. For example, the internal loading with nutrients, which accumulated in lake sediments, has been found to delay for decades the success of restoration efforts combating eutrophication or harmful algae blooms [Paerl and Otten, 2013; Schindler, 2006]. Sediment oxygen uptake and the release of reduced substances are major components of the oxygen mass balance in the water column and affect the occurrence of hypoxic or anoxic conditions [Müller et al., 2012], carbon burial in sediments [Canfield, 1994; Sobek et al., 2009], and greenhouse gas emissions to the atmosphere [Deemer et al., 2016; Tranvik et al., 2009]. The current quantitative understanding of the spatial and temporal dynamics of sediment-water exchange, however, is rather limited. The poor success rate of lake restoration efforts, for example, is most likely related to an underestimation of internal loading [Søndergaard et al., 2007].

Besides biogeochemical constraints and temperature, the temporal dynamics of sediment-water fluxes is strongly affected by near-bed flow. Turbulence controls the thickness of the diffusive concentration boundary layer at the sediment surface [Jørgensen and Revsbech, 1985; Lorke and Peeters, 2006]. The pronounced short-term (minutes to hours) variations of sediment-water fluxes, which have been observed for oxygen in rivers, lakes and marine systems, are not resolved in most biogeochemical and water quality models, although they have been shown to be of comparable magnitude as temperature-controlled seasonal variations of sediment-water fluxes in shallow lakes [Murniati et al., 2015].

Oxygen fluxes at the sediment-water interface under in situ flow conditions have been measured using the noninvasive eddy covariance (EC) technique, which was adopted from micrometeorology [Baldocchi, 2014; Foken, 2008] and was introduced as the eddy correlation technique in the aquatic environment [Berg et al., 2003]. Application of the EC technique requires fast-response sensors, which are capable of resolving concentration fluctuations caused by turbulent flows, i.e., sensors with response times in the range of $0.1-1 \mathrm{~s}$ [Lorrai et al., 2010], while being small enough to cause no disturbances of the flow field. For the aquatic environment, such sensors are readily available for temperature and dissolved oxygen only. The recent development and application of aquatic EC instrumentation has led to improved insights into the oxygen dynamics of sediment-water exchange under in situ flow conditions [Glud et al., 2016; Hume et al., 2011; McGinnis et al., 2014]. However, the complex kinetics of microbial and chemical processes under fluctuating redox 


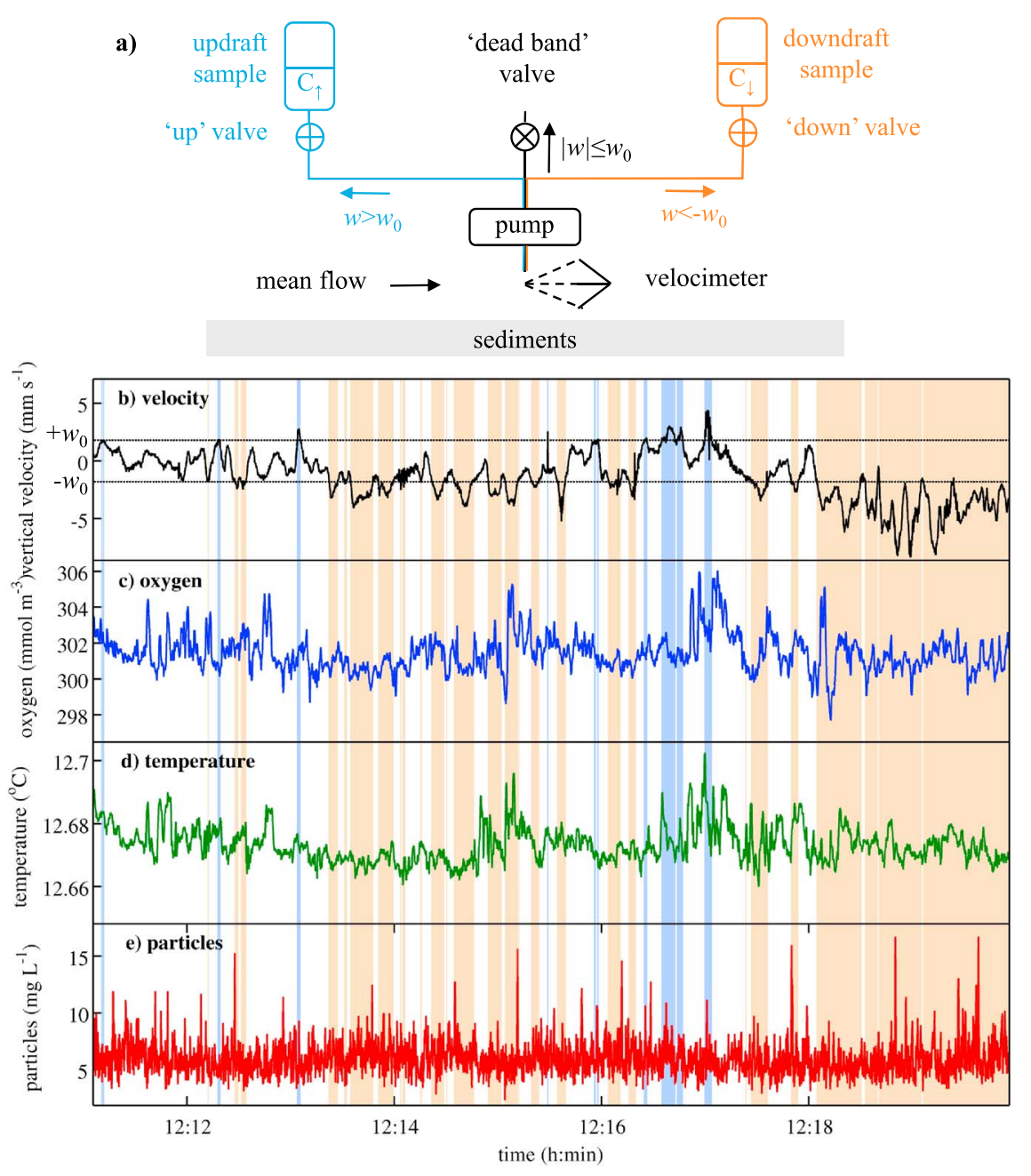

Figure 1. (a) Conceptual setup for relaxed eddy accumulation adapted from Bowling et al. [1998] for the aquatic environment. (b-e) Illustration of the sampling periods for measured time series of turbulent fluctuations of vertical velocity, dissolved oxygen concentration, temperature, and suspended matter concentration (the horizontal dashed lines in Figure $1 \mathrm{~b}$ ) represent the velocity threshold $w_{0}=0.75 \sigma_{w}$. Water is pumped continuously and collected in the updraft reservoir through the "up" valve when the turbulent fluctuation of vertical velocity $w^{\prime}$ measured by the velocimeter is larger than the threshold $w_{0}$ (blue in Figure 1a, blue background in Figures 1b-1e). The sample is collected in the downdraft reservoir through the "down" valve when $w^{\prime}<-w_{0}$ (orange in Figure 1a, red background in Figures 1b-1e). Sampled water is discarded through the "dead band" valve if $\left|w^{\prime}\right| \leq w_{0}$ (black in Figure 1a, white background in Figures 1b-1e).

conditions make questionable that fluxes of other constituents, including nutrients, follow the same temporal dynamics as dissolved oxygen.

For flux measurements in the atmospheric boundary layer, the lack of fast-response sensors for specific compounds has been overcome by relaxed eddy accumulation (REA) measurements [Baldocchi, 2014; Businger and Oncley, 1990]. In this technique, also called "conditional sampling," the high-frequency concentration measurement required for EC is replaced by accumulating gas samples from turbulent updrafts and downdrafts in separate sample containers (Figure 1). Mass fluxes of air constituents can be estimated from the concentration difference between both samples after typical accumulation periods of 0.5 to $1 \mathrm{~h}$. The sample concentrations can be measured for a broad range of different constituents either by using slowresponse field instruments or laboratory analyses. In addition, REA has the potential to yield flux estimates of many of the constituents of suspended matter, including microbes and spores and even DNA and proteins [Baldocchi, 2014].

Despite the great potential of this method, attempts to apply REA for measuring fluxes at the sediment-water interface in aquatic ecosystems have not yet been made. Here we address the question whether REA can be a 
feasible approach for sediment-water flux measurements and we provide constraints on the performance and design of such a system. We simulate REA measurements using measured EC fluxes of oxygen, temperature, and suspended matter from a shallow lake and estimate intrinsic measurement parameters. The results are compared to atmospheric applications of this method. Based on the simulations, we estimate analytical requirements for observing fluxes of a variety of solutes and discuss technical challenges in the design and the potential range of use of this technique in aquatic ecosystems.

\section{Theoretical Background}

In stationary turbulent flows, the upward eddy flux $F$ of a fluid compound is measured as the covariance of the vertical current velocity $w$ and concentration $C$ in the turbulent boundary layer:

$$
F=\operatorname{cov}(w, C)=\overline{w^{\prime} C^{\prime}}
$$

where the overbar denotes temporal averaging and primes the fluctuating components (Reynolds decomposition: $w^{\prime}=w-\bar{w}$ and $C^{\prime}=C-\bar{C}$. Concentration and velocity fluctuations must be measured in the same sampling volume and resolve all flux-contributing turbulent eddies. In REA measurements, a sampling pump and one or more fast-switching valves are used to accumulate two separate samples from updrafts and downdrafts by conditional sampling (Figure 1). Mass fluxes can be estimated from the difference between the mean concentrations in the updraft $\left(\overline{C_{\uparrow}}\right)$ and downdraft $\left(\overline{C_{\downarrow}}\right)$ samples, as

$$
F=b \sigma_{w}\left(\overline{C_{\uparrow}}-\overline{C_{\downarrow}}\right)
$$

where $b$ is a dimensionless empirical coefficient and $\sigma_{w}$ the standard deviation of the vertical flow velocity $\left(\sigma_{w}=\left(\overline{w^{\prime 2}}\right)^{1 / 2}\right)$ [Hornsby et al., 2009; Olofsson et al., 2005]. To increase the concentration difference between updraft and downdraft samples, a velocity threshold $\left(w_{0}\right)$ is frequently applied and samples are collected only if the magnitude of the vertical velocity exceeds this threshold ("dead band" around $w^{\prime}=0 \mathrm{~m} \mathrm{~s}^{-1}$ ). This slightly reduces the required resolution of the concentration measurements [Businger and Oncley, 1990] and reduces the number of switches of the valves that control the conditional sampling and errors resulting from transient flow in the sampling tubes.The determination of the coefficient $b$ in equation (2) has received considerable attention in atmospheric applications, while no estimates are available for aquatic environments. With the assumption of cospectral similarity, $b$ is independent of the type of the transported scalar. By further assuming Gaussian probability distributions for $w^{\prime}$ and $C^{\prime}$, Wyngaard and Moeng [1992] showed that it equals a constant $b \approx 0.63$. The coefficient can be estimated experimentally for various scalars by combining equations (1) and (2):

$$
b=\frac{\overline{w^{\prime} C^{\prime}}}{\sigma_{w}\left(\overline{C_{\uparrow}}-\overline{C_{\downarrow}}\right)}
$$

either directly if REA and EC measurements are performed simultaneously [Pattey et al., 1993], or by simulating REA sampling with EC measurements [Ammann and Meixner, 2002; Businger and Oncley, 1990]. Estimates of $b$ based on measured fluxes of heat, water vapor and carbon dioxide in the atmospheric boundary layer were in close agreement and ranged within 0.56-0.58 for unstable and near-neutral daytime conditions [Businger and Oncley, 1990; Pattey et al., 1993]. For individual $30 \mathrm{~min}$ flux estimates, the values showed large scatter, e.g., $0.49 \pm 0.13$ in stable nighttime conditions [Pattey et al., 1995]. Ammann and Meixner [2002] showed that the dependence of the coefficient $b$ on atmospheric stability can be described using the nondimensional length scale $z / L$ with $z$ being the measurement height above ground and $L$ the MoninObukhov length scale. They found an exponential relationship between the coefficient $b$ and the velocity threshold normalized by the standard deviation of vertical velocity:

$$
b_{\text {fit }}\left(\frac{w_{0}}{\sigma_{w}}\right)=b_{\infty}+\left(b_{0}-b_{\infty}\right) \exp \left(-a \frac{w_{0}}{\sigma_{w}}\right) \text { for } 0 \leq \frac{w_{0}}{\sigma_{w}} \leq 2
$$

with $b_{0}$ denoting the value of the coefficient $b$ with zero dead band $\left(w_{0}=0 \mathrm{~m} \mathrm{~s}^{-1}\right), b_{\infty}$ its asymptotic value for $w_{0}>>\sigma_{w}$ and $a$ an attenuation coefficient, and all coefficients depending upon atmospheric stability. 


\section{Materials and Methods}

\subsection{Data}

We used EC measurements of flow velocity, temperature, dissolved oxygen, and suspended solid concentrations at the sediment-water interface of a riverine lake (Havel River, Germany) to simulate REA flux measurements. Current velocity, temperature, and dissolved oxygen concentration were measured at $8 \mathrm{~Hz}$ with an acoustic Doppler velocimeter (ADV), a microthermistor and Clark-type oxygen microelectrodes during 19 instrument deployments at four different sampling sites with 30 to $400 \mathrm{~min}$ duration each. The measurements, which are described at greater detail in Murniati et al. [2015], were obtained at a distance of about $15 \mathrm{~cm}$ from the sediment surface at water depths between 3.3 and $7.7 \mathrm{~m}$. The average current speed ranged between 1 and $5 \mathrm{~cm} \mathrm{~s}^{-1}$ and 30 min standard deviation of the vertical velocity $\sigma_{w}$ between 0.5 and $5 \mathrm{~mm} \mathrm{~s}^{-1}$.

Suspended solid concentrations were estimated from acoustic backscatter strength measured by the ADV using a calibration against measured concentrations obtained for Lake Constance [Hofmann et al., 2011]. We computed EC fluxes of heat (temperature), dissolved oxygen, and suspended matter using equation (1) for 104 segments of 30 min measurement duration as described in Murniati et al. [2015]: two axis rotation of the velocity vectors in each segment to compensate for imperfect leveling of the instruments with the sediment-water interface, subtraction of a 1 min running average for estimating turbulent velocity and concentration fluctuations. In addition, the delay between vertical velocity and concentration fluctuation measurements due to physical sensor separation was corrected by shifting both time series relative to each other within a $2 \mathrm{~s}$ window for maximizing the flux magnitudes [Donis et al., 2015].

\subsection{Simulation of the Coefficient $b$}

We simulated the differences in dissolved oxygen concentration, temperature, and suspended matter concentration that would be observed for conditional sampling of updraft and downdraft eddy transport $\left(\overline{C_{\uparrow}}\right.$ and $\overline{C_{\downarrow}}$ ) during $30 \mathrm{~min}$ sample accumulation periods. To do this, we compared the turbulent fluctuations of the measured vertical velocity to the velocity threshold $w_{0}$ (Figure 1 ). The concentration and temperature time series were shifted relative to velocity fluctuations by the same time shifts as during the processing of EC fluxes. The coefficients $b$ were computed using equation (3) for normalized velocity thresholds $w_{0} / \sigma_{w}$ ranging between 0 and 2 and then fitted to equation (4) to obtain compound-specific values of the coefficients $b_{0}, b_{\infty}$ and $a$.

We investigated whether the coefficient $b$ depends on properties of the turbulent boundary layer flow, namely, whether its value $b_{0}$ computed without velocity threshold varies with the nondimensional boundary layer coordinate $z u^{*} / v$, where $z$ is the vertical distance between the sampling volume and the sediment surface, $u^{*}$ is the shear velocity, computed as $u^{*}=\sqrt{-\overline{u^{\prime} w^{\prime}}}$, and $v$ is the kinematic viscosity of water.

\subsection{Simulation of REA Fluxes}

We simulated the REA fluxes for normalized velocity thresholds $\left(w_{0} / \sigma_{w}\right)$ between 0 and 2 . For each threshold and variable, we used the corresponding coefficient $b_{\text {fit }}$ (equation (4)) and we compared two different processing schemes. The first one, which we will refer to as "processing with time shift correction," is identical with the processing that was applied for the computation of EC fluxes and coefficient $b$ : two axis velocity rotation of each segment, time shifting of concentrations and temperature relative to velocity fluctuations. Because the technical implementation of the time shift correction into a REA measurement system may not be feasible, REA simulations were additionally performed with a velocity processing that could also be applied in situ, which we will refer to as "processing without time shift": the velocity vectors were rotated using fixed angles for the entire data set and no time shift correction was applied to the concentration and temperature time series.

To find an optimum normalized velocity threshold $\left(w_{0} / \sigma_{w}\right)^{*}$ for REA sampling, we minimized the mean absolute error (MAE) between REA and EC fluxes normalized by the absolute value of the mean EC flux. Whereas in atmospheric REA measurements, the optimal velocity threshold $w_{0}$ is calculated from the velocity standard deviation in the previous data segment; here as we did before, we used the measured velocities of the same data segment, which made it possible to compute fluxes for all available segments. 

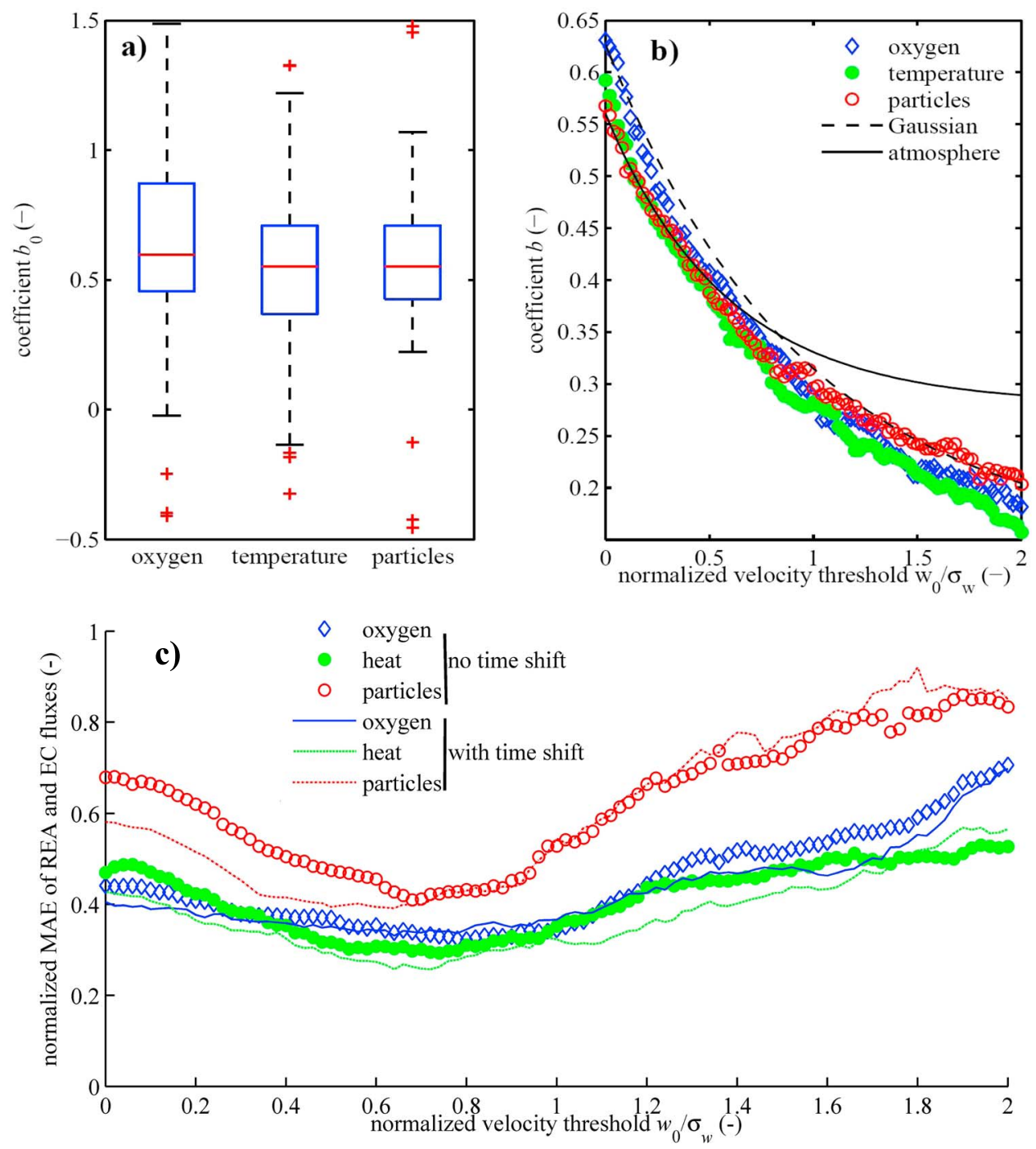

d) oxygen

e) heat

f) particles
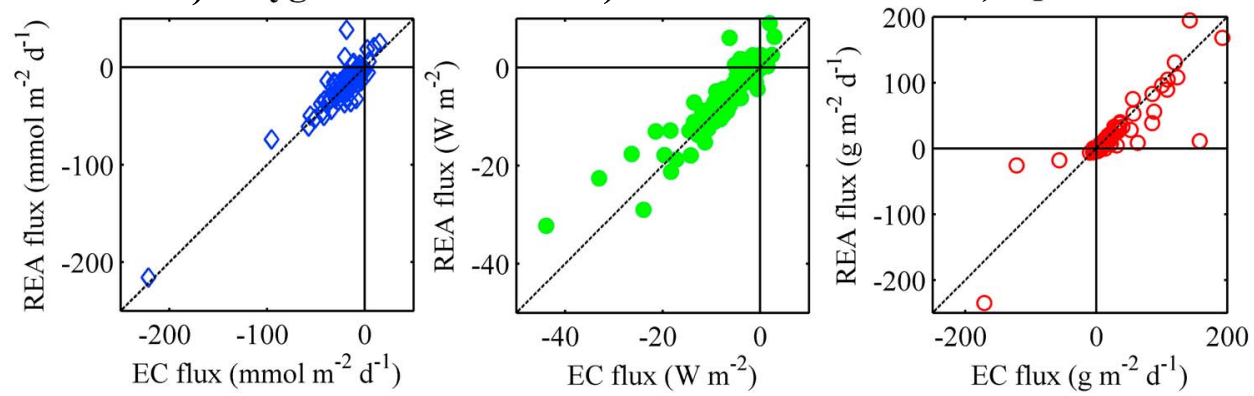

Figure 2. (a) Distributions of the coefficients $b_{0}$ for oxygen, temperature, and suspended matter $(n=104)$. The boxes demarcate the 25 th and 75 th percentiles and the whiskers the $95 \%$ confidence intervals; median values are marked as red horizontal lines and outliers are shown as red crosses. (b) Median values of the coefficient $b$ as a function of the normalized velocity threshold $w_{0} / \sigma_{w}$ : the solid line shows the dependence observed in the atmosphere for unstable atmospheric conditions and the dashed line for the theoretical case of a joint Gaussian distribution of velocity and concentration fluctuations [Ammann and Meixner, 2002]. (c) Mean absolute error (MAE) between simulated REA and measured EC fluxes, normalized by the mean EC flux, for dissolved oxygen, heat, and suspended matter as a function of the normalized velocity threshold ( $n=104)$ and for both processing schemes for REA. (d-f) REA versus EC fluxes of oxygen, heat, and suspended matter for the optimum normalized velocity of 0.75 (processing without time shift correction); MAE are $33 \%, 30 \%$ and $42 \%$ of mean EC fluxes respectively. 


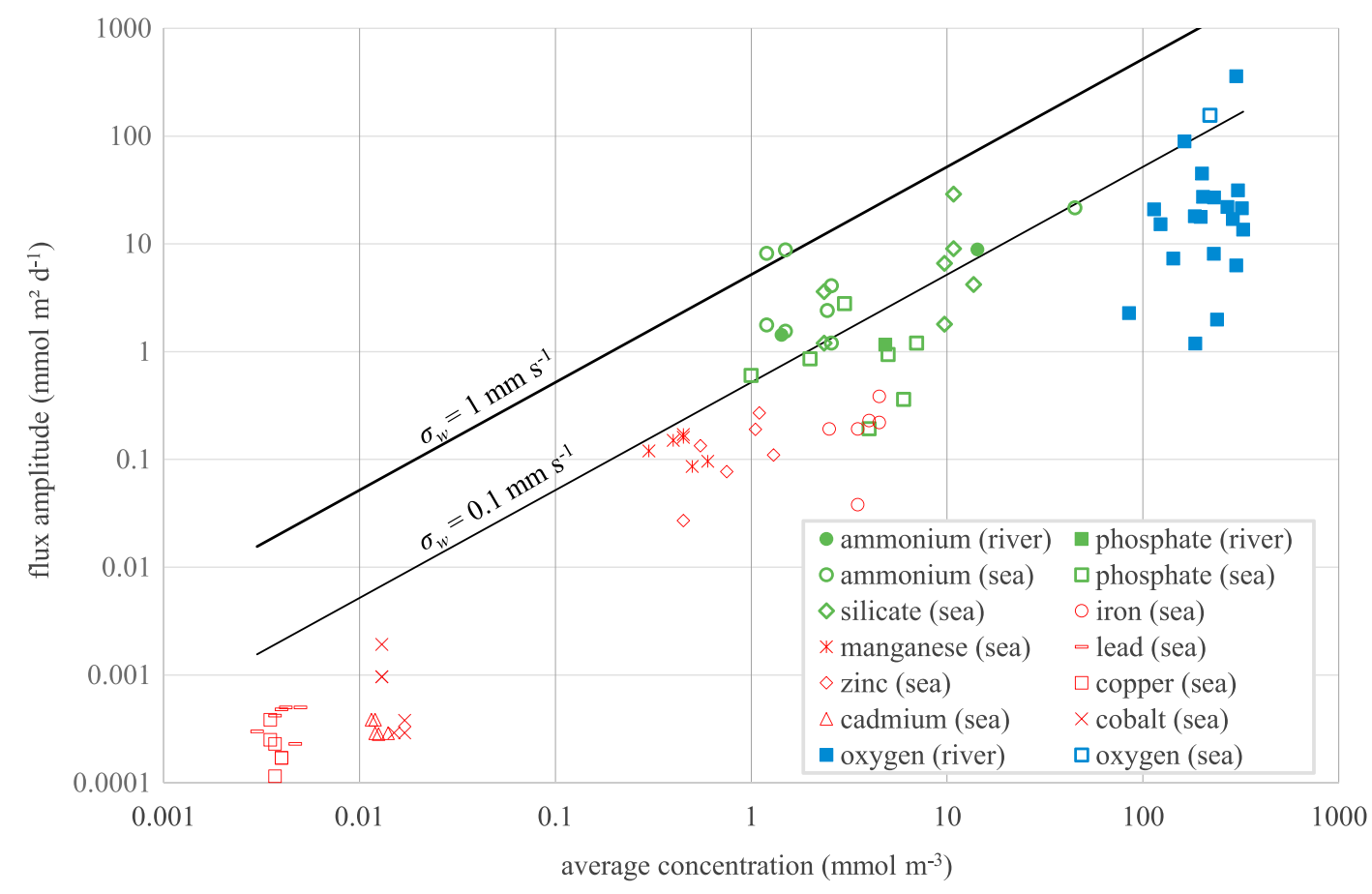

Figure 3. The lower quantification limit of REA flux measurements for different levels of turbulence $\sigma_{w}$ and a relative analytical precision of concentration measurements of $10 \%$ (solid lines) is compared to benthic chamber fluxes reported in literature. Filled symbols denote data from freshwater systems and open symbols data from coastal waters. Green indicates main nutrients: ammonium, soluble reactive phosphorus, silicate [Baudinet et al., 1990; Gruneberg et al., 2015; Sakamaki et al., 2006]; red denotes metal ions, $\mathrm{Fe}^{2+}, \mathrm{Mn}^{2+}, \mathrm{Pb}^{2+}, \mathrm{Zn}^{2+}, \mathrm{Cu}^{2+}, \mathrm{Cd}^{2+}$, and $\mathrm{Co}^{2+}$ [Hellali et al., 2015]. Oxygen fluxes were added for comparison in blue. They were measured in benthic chambers on a tidal flat [Sakamaki et al., 2006] and by eddy covariance in a lake from this study and in a river [Berg et al., 2013] (this last is the highest flux shown in the figure). Note that the lower quantification limit is the same for $\sigma_{w}=0.1 \mathrm{~mm} \mathrm{~s}^{-1}$ and $\Delta C / \bar{C}=10 \%$ as for $\sigma_{w}=1 \mathrm{~mm} \mathrm{~s}^{-1}$ and $\Delta C / \bar{C}=1 \%$ (equation (5)). More information about the selected flux values is available in supporting information (Table S3).

\subsection{Lower Quantification Limit of REA Fluxes}

To assess the analytical requirements for observing fluxes with REA in aquatic environments, we estimated their lower quantification limit $L Q_{\mathrm{REA}}$ and compared it with flux estimates from literature. The lower quantification limit was determined by replacing the concentration difference in equation (2) by the twofold analytical precision of concentration measurements $\Delta C$. Since precision depends on the substance, the analytical technique and the measured concentration, we used an approximate value for the relative measurement precision of $(\Delta C / \bar{C}) \approx 10 \%$, where $\bar{C}$ is the average of the concentrations in the two samples. Finally, the lower quantification limit of REA fluxes can be estimated as follows:

$$
L Q_{\mathrm{REA}}=2 b_{\mathrm{fit}}\left(\left(w_{0} / \sigma_{w}\right)^{*}\right)(\Delta \mathrm{C} / \overline{\mathrm{C}}) \sigma_{w} \bar{C},
$$

where the coefficient $b_{\text {fit }}$ was computed for the optimum velocity threshold $\left(w_{0} / \sigma_{w}\right)^{*}$. This quantification limit was computed for two levels of turbulence, which were expressed as the standard deviation of the vertical velocity $\sigma_{w}=0.1$ and $1 \mathrm{~mm} \mathrm{~s}^{-1}$ ( $\sigma_{w}$ varied between 0.5 and $5 \mathrm{~mm} \mathrm{~s}^{-1}$ in the measurements).

\section{Results}

The coefficient $b_{0}$ estimated with no velocity threshold $\left(w_{0}=0 \mathrm{~mm} \mathrm{~s}^{-1}\right)$ is of comparable magnitude for oxygen, temperature, and suspended matter (Figure 2a). The median values are $0.60,0.55$, and 0.55 with interquartile ranges of $0.40,0.34$, and 0.29 , respectively $(n=104)$. The coefficients $b_{0}$ were not significantly correlated with the nondimensional measurement height $z u^{*} / v\left(n=33, r^{2}=0.05, p=0.2\right)$, as expected for a fully mixed layer. There was a consistent dependence of the coefficients $b$ on the threshold velocity $w_{0}$ for all three fluxes (Figure 2b), which followed the dependence described by equation (4) and the 
theoretical relationship for joint Gaussian distributions derived by Ammann and Meixner [2002]. Least squares fits of the observed relationships to equation (4) yielded the following parameters: for oxygen: $b_{\infty}=0.152$, $a=1.35$; for temperature: $b_{\infty}=0.0935, a=0.954$; and for suspended matter: $b_{\infty}=0.172, a=1.13(n=101$, $r^{2}=0.99$ for each fit).

Simulated REA fluxes showed best agreement with EC fluxes for normalized velocity thresholds $\left(w_{0} / \sigma_{w}\right)$ between 0.7 and 0.8 for all three variables (Figure 2c), corresponding to a threshold velocity between 0.4 and $4 \mathrm{~mm} \mathrm{~s}^{-1}$ for the different data segments. For a Gaussian distribution of velocity fluctuations, a threshold of $0.75 \sigma_{w}$ implies that sampling is conducted during $45 \%$ of the total measurement time. At this threshold, the mean absolute error (MAE) between REA and EC fluxes was around 30\% for temperature and oxygen, a bit higher for suspended matter. Besides considerable scatter of individual estimates, no systematic deviations between REA and EC fluxes were observed (Figures $2 \mathrm{~d}-2 \mathrm{f}$, processing without time shift correction). Moreover, both processing schemes for REA resulted in comparable differences between REA and EC fluxes (Figure 2c): at zero velocity threshold, the normalized MAE differed by 4 percentage points for oxygen and heat, and by 10 percentage points for particles. The effect of the applied processing was even smaller (between 0 and 3 percentage points) at the optimum velocity threshold.

To assess the feasibility of relaxed eddy accumulation in aquatic ecosystems, we compared its lower quantification limit to flux magnitudes of dissolved nutrients and metal ions reported in literature (Figure 3). They were measured in unknown turbulence conditions, in stirred or unstirred benthic flux chambers in different types of aquatic ecosystems, including estuaries, rivers, and lakes. Most reported fluxes fall below the lower quantification limit for a turbulence level $\sigma_{w}=1 \mathrm{~mm} \mathrm{~s}^{-1}$ and for the assumed relative analytical precision of $10 \%$.

\section{Discussion and Conclusions}

The purpose of this study was to investigate whether relaxed eddy accumulation is a feasible measurement technique for measuring fluxes at the sediment-water interface in aquatic ecosystems. Our results showed that similar to the atmospheric boundary layer, the coefficient $b$ is constant at a given velocity threshold and depends neither on the measured quantity nor on the hydrodynamic conditions. It decays exponentially with increasing velocity threshold, and the REA fluxes simulated with a normalized threshold between 0.7 and 0.8 showed best agreement with measured EC fluxes.

The similarity between the present findings and those obtained in the atmosphere, especially in the extensive reanalysis of eddy-covariance data by Ammann and Meixner [2002], is surprisingly high. We found close agreement between the median values of the coefficient $b_{0}$ without velocity threshold $0.57 \pm 0.03$ in this study for oxygen, temperature, and suspended matter) and the value reported by Ammann and Meixner [2002] $(0.56 \pm 0.01)$ for fluxes of carbon dioxide, temperature, and water vapor under unstable atmospheric conditions. The decrease of the coefficient $b$ for increasing velocity threshold is also very similar (Figure 2b), as well as the normalized velocity threshold for the best match between REA and EC fluxes (0.7-0.8 in the present study (Figure 2c) and 0.5-0.8 in the atmosphere [Tsai et al., 2012]). However, the interquartile range of the distributions of the coefficient $b_{0}$ is much larger in the present study (around 0.3, $n=104$ ) than the range of 0.05-0.1 found by Ammann and Meixner [2002] or by Tsai et al. [2012] for different variables under unstable atmospheric conditions ( $n=500-1000$ and 220-1200, respectively). Particularly for high velocity thresholds, we found lower values of the coefficient $b$ than in their results but better agreement with the theoretical dependence for joint Gaussian distributions of $w^{\prime}$ and $C^{\prime}$ (Figure 2b).

The comparison of the required analytical precision for measuring the concentration difference in the REA samples suggests that analytical precision can be a major limiting factor in REA applications in aquatic environments (Figure 3). The results indicate that metal and nutrient fluxes at the high end of observations reported in the literature may be resolved in low-energy environments, such as lakes. However, sedimentwater fluxes reported in the literature are mainly based on measurements with benthic chambers, where the reduced turbulence may cause an underestimation of fluxes. For example, Berg et al. [2013] measured fourfold higher oxygen fluxes with eddy covariance under in situ flow conditions than in simultaneously deployed benthic chambers. This suggests that fluxes could also be more easily resolved in situ with REA than with benthic chambers. Moreover, the lower quantification limit of REA measurements could be reduced by 
using high-precision analytical techniques like differential analytical methods, or field analysis equipment for avoiding sample evolution during transportation and storage. Alternatively, the lower quantification limit can be reduced by sampling closer to the sediment surface (the simulations are based on measurements conducted at a distance of $15 \mathrm{~cm}$ from the sediment-water interface): under stationary conditions, the solute flux is uniform within the turbulent boundary layer, and velocity fluctuations decrease while concentration gradients increase toward the sediment surface. Obviously, an optimal distance is to be found, since too low turbulence hinders the measurement of vertical velocity fluctuations and the use of REA.

The implementation of a time shift correction for the spatial separation between velocimeter and sample intake, as well as the two axis velocity rotation of each segment to correct sensor misalignment, would be technically challenging. However, our simulations showed that these corrections did not reduce the discrepancy between REA and EC fluxes if an optimal velocity threshold is used. This is consistent with typical REA processing in the atmosphere, where a two axis velocity rotation is based on previously recorded velocities and no time shift correction is applied [Foken, 2008]. For future REA applications in the aquatic environment we propose the following preprocessing, which can be applied in situ: on a first segment before the beginning of REA sampling, a two-axis rotation aligns the velocity measurements with the mean current; on each following segment, vertical velocity fluctuations are continuously filtered by subtracting the running mean of velocity over the previous minute and sampling is based on a threshold velocity computed as 0.7-0.8 times the standard deviation of the vertical velocity fluctuations $\sigma_{w}$ from the previous segment. This constitutes a promising in situ preprocessing of velocities to condition REA sampling.

Our findings indicate that REA has a great potential for in situ measurements of the dynamics of fluxes at the sediment-water interface at high temporal resolution, provided that the technical challenges of sampling and measuring target constituents at instances of updrafts and downdrafts are overcome. First, the hydraulic perturbation of the flow by the sample intake must be minimized, while providing a sufficiently high flow rate for sample accumulation within a reasonable measurement period, typically $0.8 \mathrm{~L} \mathrm{~h}^{-1}$ for two $200 \mathrm{~mL}$ sample containers over $30 \mathrm{~min}$. The optimum design will probably depend on the mean current velocity, which is generally lower in shallow lakes and canals than in rivers, estuaries, and coastal waters, and on the stability of current direction. Constant flow direction constitutes optimum conditions for REA measurements, making it possible to limit the blocking effect of the sampling tube by locating it downstream of the velocimeter, whereas measurements may be delicate if the direction of flow changes frequently, such as in lakes. Similar to EC flux estimates in aquatic environments, REA measurements could be strongly affected by the presence of progressive waves, which cause relatively large and periodic variations of vertical velocity without significant flux contributions [Reimers et al., 2016]. While spurious flux contributions from surface waves can, at least partially, be removed during the postprocessing of EC measurements [Berg et al., 2015], such a correction would not be possible for accumulated REA samples. While high-frequency progressive waves are not present in the atmospheric boundary layer, their presence may cause a significant bias of REA flux estimates in wave-affected aquatic environments (nearshore and coastal zones), where the suitability of REA flux measurements should be carefully tested. Technical solutions for fast-switching valves operating in turbid water and automated replacement of sample containers for sequential flux measurements need to be developed. Last but not least, if the sample analysis is not performed by field analysis equipment, sample preservation deserves particular consideration in the technical design of REA systems for the aquatic environment as well as in further assessments of the technique's suitability for measuring sediment-water fluxes of specific compounds.

Acknowledgments

Bruno Lemaire received the support of the EU in the framework of the MarieCurie FP7 COFUND People Programme, through the award of an AgreenSkills fellowship under grant agreement 267196. We thank Erni Murniati and Sebastian Geissler who collected the data and Tingting Ji for her assistance during this work. Supporting information are included as a table and two data sets. The eddy covariance data necessary to reproduce the simulations are available from the first author upon request.

\section{References}

Ammann, C., and F. X. Meixner (2002), Stability dependence of the relaxed eddy accumulation coefficient for various scalar quantities, J. Geophys. Res., 107(D8), 4071, doi:10.1029/2001JD000649.

Baldocchi, D. (2014), Measuring fluxes of trace gases and energy between ecosystems and the atmosphere-The state and future of the eddy covariance method, Global Change Biol., 20(12), 3600-3609, doi:10.1111/gcb.12649.

Baudinet, D., E. Alliot, B. Berland, C. Grenz, M. R. Plantecuny, R. Plante, and C. Salenpicard (1990), Incidence of mussel culture on biogeochemical fluxes at the sediment-water interface, Hydrobiologia, 207, 187-196, doi:10.1007/bf00041456.

Berg, P., H. Røy, F. Janssen, V. Meyer, B. B. Jørgensen, M. Hüttel, and D. de Beer (2003), Oxygen uptake by aquatic sediments measured with a novel non-invasive eddy-correlation technique, Mar. Ecol. Prog. Ser., 261, 75-83, doi:10.3354/meps261075.

Berg, P., M. H. Long, M. Huettel, J. E. Rheuban, K. J. McGlathery, R. W. Howarth, K. H. Foreman, A. E. Giblin, and R. Marino (2013), Eddy correlation measurements of oxygen fluxes in permeable sediments exposed to varying current flow and light, Limnol. Oceanogr., 58(4), 1329-1343, doi:10.4319/lo.2013.58.4.1329. 
Berg, P., C. E. Reimers, J. H. Rosman, M. Huettel, M. L. Delgard, M. A. Reidenbach, and H. T. Özkan-Haller (2015), Technical note: Time lag correction of aquatic eddy covariance data measured in the presence of waves, Biogeosciences, 12(22), 6721-6735, doi:10.5194/bg-126721-2015.

Bowling, D. R., A. A. Turnipseed, A. C. Delany, D. D. Baldocchi, J. P. Greenberg, and R. K. Monson (1998), The use of relaxed eddy accumulation to measure biosphere-atmosphere exchange of isoprene and other biological trace gases, Oecologia, 116, 306-315.

Businger, J. A., and S. P. Oncley (1990), Flux measurement with conditional sampling, J. Atmos. Ocean. Technol., 7(2), 349-352, doi:10.1175/ 1520-0426(1990)007<0349:FMWCS>2.0.CO;2

Canfield, D. E. (1994), Factors influencing organic-carbon preservation in marine sediments, Chem. Geol., 114(3-4), 315-329, doi:10.1016/ 0009-2541(94)90061-2.

Deemer, B. R., J. A. Harrison, S. Li, J. J. Beaulieu, T. DelSontro, N. Barros, J. F. Bezerra-Neto, S. M. Powers, M. A. dos Santos, and J. A. Vonk (2016), Greenhouse gas emissions from reservoir water surfaces: A new global synthesis, Bioscience, 66(11), 949-964, doi:10.1093/biosci/ biw117.

Donis, D., et al. (2015), An assessment of the precision and confidence of aquatic eddy correlation measurements, J. Atmos. Ocean. Technol., 32(3), 642-655, doi:10.1175/JTECH-D-14-00089.1.

Foken, T. (2008), Micrometeorology, translated from German by C. Nappo, Springer, Berlin.

Glud, R. N., P. Berg, H. Stahl, A. Hume, M. Larsen, B. D. Eyre, and P. L. M. Cook (2016), Benthic carbon mineralization and nutrient turnover in a Scottish Sea loch: An integrative in situ study, Aquat. Geochem., 22(5), 443-467, doi:10.1007/s10498-016-9300-8.

Gruneberg, B., T. Dadi, C. Lindim, and H. Fischer (2015), Effects of nitrogen and phosphorus load reduction on benthic phosphorus release in a riverine lake, Biogeochemistry, 123(1-2), 185-202, doi:10.1007/s10533-014-0062-3.

Hellali, M. A., N. Zaaboub, W. Oueslati, A. Added, and L. Aleya (2015), Diagenetic processes and sediment-water exchanges of heavy metals in the Mejerda River Delta (Gulf of Tunis), Environ. Earth Sci., 74(9), 6665-6679, doi:10.1007/s12665-015-4667-1.

Hofmann, H., A. Lorke, and F. Peeters (2011), Wind and ship wave-induced resuspension in the littoral zone of a large lake, Water Resour. Res., 47, W09505, doi:10.1029/2010WR010012.

Hornsby, K. E., M. J. Flynn, J. R. Dorsey, M. W. Gallagher, R. Chance, C. E. Jones, and L. J. Carpenter (2009), A relaxed eddy accumulation (REA)GC/MS system for the determination of halocarbon fluxes, Atmos. Meas. Tech., 2(2), 437-448, doi:10.5194/amt-2-437-2009.

Hume, A., P. Berg, and K. J. McGlathery (2011), Dissolved oxygen fluxes and ecosystem metabolism in an eelgrass (Zostera Marina) meadow measured with the eddy correlation technique, Limnol. Oceanogr., 56, 86-96, doi:10.4319/lo.2011.56.1.0086.

Jørgensen, B. B., and N. P. Revsbech (1985), Diffusive boundary layers and the oxygen uptake of sediments and detritus, Limnol. Oceanogr., 30(1), 111-122, doi:10.4319/lo.1985.30.1.0111.

Lorke, A., and F. Peeters (2006), Toward a unified scaling relation for interfacial fluxes, J. Phys. Oceanogr., 36, 955-961, doi:10.1175/JPO2903.1.

Lorrai, C., D. F. McGinnis, P. Berg, A. Brand, and A. Wuest (2010), Application of oxygen eddy correlation in aquatic systems, J. Atmos. Ocean. Technol., 27(9), 1533-1546, doi:10.1175/2010jtecho723.1.

McGinnis, D. F., S. Sommer, A. Lorke, R. N. Glud, and P. Linke (2014), Quantifying tidally driven benthic oxygen exchange across permeable sediments: An aquatic eddy correlation study, J. Geophys. Res. Oceans, 119, 6918-6932, doi:10.1002/2014JC010303.

Müller, B., L. D. Bryant, A. Matzinger, and A. Wüest (2012), Hypolimnetic oxygen depletion in eutrophic lakes, Environ. Sci. Technol., 46(18), 9964-9971, doi:10.1021/es301422r.

Murniati, E., S. Geissler, and A. Lorke (2015), Short-term and seasonal variability of oxygen fluxes at the sediment-water interface in a riverine lake, Aquat. Sci., 77(2), 183-196, doi:10.1007/s00027-014-0362-7.

Olofsson, M., J. Sommar, E. Ljungstrom, M. Andersson, and I. Wangberg (2005), Application of relaxed eddy accumulation technique to quantify $\mathrm{Hg}^{0}$ fluxes over modified soil surfaces, Water Air Soil Pollut., 167(1-4), 331-352, doi:10.1007/s11270-005-0012-8.

Paerl, H. W., and T. G. Otten (2013), Harmful cyanobacterial blooms: Causes, consequences, and controls, Microb. Ecol., 65(4), 995-1010, doi:10.1007/s00248-012-0159-y.

Pattey, E., R. L. Desjardins, and P. Rochette (1993), Accuracy of the relaxed eddy-accumulation technique, evaluated using $\mathrm{CO}_{2}$ flux measurements, Boundary-Layer Meteorol., 66(4), 341-355, doi:10.1007/bf00712728.

Pattey, E., A. J. Cessna, R. L. Desjardins, L. A. Kerr, P. Rochette, G. Stamour, T. Zhu, and K. Headrick (1995), Herbicides volatilization measured by the relaxed eddy-accumulation technique using 2 trapping media, Agric. For. Meteorol., 76(3-4), 201-220, doi:10.1016/01681923(95)02225-m

Reimers, C. E., H. T. Özkan-Haller, A. T. Albright, and P. Berg (2016), Microelectrode velocity effects and aquatic eddy covariance measurements under waves, J. Atmos. Ocean. Technol., 33(2), 263-282, doi:10.1175/jtech-d-15-0041.1.

Sakamaki, T., O. Nishimura, and R. Sudo (2006), Tidal time-scale variation in nutrient flux across the sediment-water interface of an estuarine tidal flat, Estuar. Coast. Shelf Sci., 67(4), 653-663, doi:10.1016/j.ecss.2006.01.005.

Schindler, D. W. (2006), Recent advances in the understanding and management of eutrophication, Limnol. Oceanogr., 51(1 part2), 356-363, doi:10.4319/lo.2006.51.1_part_2.0356.

Sobek, S., E. Durisch-Kaiser, R. Zurbrugg, N. Wongfun, M. Wessels, N. Pasche, and B. Wehrli (2009), Organic carbon burial efficiency in lake sediments controlled by oxygen exposure time and sediment source, Limnol. Oceanogr., 54(6), 2243-2254, doi:10.4319/lo.2009.54.6.2243.

Søndergaard, M., E. Jeppesen, T. L. Lauridsen, C. Skov, E. H. Van Nes, R. Roijackers, E. Lammens, and R. O. B. Portielje (2007), Lake restoration: Successes, failures and long-term effects, J. Appl. Ecol., 44(6), 1095-1105, doi:10.1111/j.1365-2664.2007.01363.x.

Tranvik, L. J., et al. (2009), Lakes and reservoirs as regulators of carbon cycling and climate, Limnol. Oceanogr., 54(6), 2298-2314, doi:10.4319/ lo.2009.54.6_part_2.2298.

Tsai, J.-L., B.-J. Tsuang, P.-H. Kuo, C.-Y. Tu, C.-L. Chen, M.-T. Hsueh, C.-S. Lee, M.-H. Yao, and M.-L. Hsueh (2012), Evaluation of the relaxed eddy accumulation coefficient at various wetland ecosystems, Atmos. Environ., 60, 336-347, doi:10.1016/j.atmosenv.2012.06.081.

Wyngaard, J. C., and C.-H. Moeng (1992), Parameterizing turbulent diffusion through the joint probability density, Boundary-Layer Meteorol., 60(1), 1-13, doi:10.1007/bf00122059. 